\title{
G-Quadruplex Induction by the Hairpin Pyrrole-Imidazole Polyamide Dimer
}

\section{$\operatorname{AUTHOR}(\mathrm{S})$ :}

Obata, Shunsuke; Asamitsu, Sefan; Hashiya, Kaori; Bando, Toshikazu; Sugiyama, Hiroshi

\section{CITATION:}

Obata, Shunsuke ... [et al]. G-Quadruplex Induction by the Hairpin Pyrrole-Imidazole Polyamide Dimer. Biochemistry 2018, 57(5): 498-502

\section{ISSUE DATE:}

2018-02-06

URL:

http://hdl.handle.net/2433/230865

\section{RIGHT:}

This document is the Accepted Manuscript version of a Published Work that appeared in final form in 'Biochemistry', copyright (c) American Chemical Society after peer review and technical editing by the publisher. To access the final edited and published work see https://doi.org/10.1021/acs.biochem.; The full-text file will be made open to the public on 13 December 2018 in accordance with publisher's 'Terms and Conditions for Self-Archiving'.; この論文は出版社版て ありません。引用の際には出版社版をご確認ご利用ください。;This is not the published version. Please cite only the published version. 


\title{
G-Quadruplex Induction by Hairpin Pyrrole-Imidazole Polyamide Dimer
}

\author{
Shunsuke Obata ${ }^{\mathrm{a}}$, Sefan Asamitsu ${ }^{\mathrm{a}}$, Kaori Hashiya ${ }^{\mathrm{a}}$, Toshikazu Bando ${ }^{*}$,a , and Hiroshi Sugiyama ${ }^{*}, \mathrm{a}, \mathrm{b}$ \\ ${ }^{a}$ Department of Chemistry, Graduate School of Science, Kyoto University, Kitashirakawa-Oiwakecho, Sakyo-ku, Kyoto 606- \\ 8502, Japan \\ ${ }^{\mathrm{b}}$ Institute for Integrated Cell-Material Sciences (WPI-iCeMS), Kyoto University, Yoshida-Ushinomiyacho, Sakyo-ku, Kyoto \\ 606-8501, Japan
}

Supporting Information Placeholder

\begin{abstract}
G-quadruplex (G4) is one type of higher-order structure of nucleic acids and is thought to play important roles in various biological events such as regulation of transcription and inhibition of DNA replication. Pyrrole-imidazole polyamides (PIPs) are programmable small molecules that can sequencespecifically bind with high affinity to the minor groove of doublestranded (ds) DNA. Herein, we designed head-to-head hairpin PIP dimers and their target dsDNA in a model G4-forming sequence. Using an electrophoresis mobility shift assay and transcription arrest assay, we found that PIP dimers could induce the structural change to G4 DNA from dsDNA through the recognition by one PIP dimer molecule of two duplex binding sites flanking both ends of the G4-forming sequence. This induction ability was dependent on the linker length. This is the first study to induce G4 formation using PIPs, which are known to be dsDNA binders. The results reported here suggest that selective G4 induction in native sequences may be achieved with PIP dimers by applying the same design strategy.
\end{abstract}

It is known that nucleic acids can form higher-order structures including triplex, ${ }^{1}$ cruciform, ${ }^{2}$ and i-motif structures. $^{3}$ A Gquadruplex (G4) is one such structure and is composed of Gquartet planes formed by four guanines via Hoogsteen hydrogen bonds. ${ }^{4}$ This structure can be observed in G-rich sequences such as telomere and promoter regions of some genes. ${ }^{4}$ For example, a human telomeric DNA has (TTAGGG)-repeating sequences, which can form G4 structures and cause telomere end protection and telomerase inhibition. ${ }^{5} \mathrm{G} 4$ formation in the promoter region of the $c-M y c$ gene leads to regulation of transcription or inhibition of DNA replication. ${ }^{6}$ Consequently, the $\mathrm{G} 4$ structure is considered to play important roles in various biological events.

For the past few decades, our group has studied pyrroleimidazole polyamides (PIPs), first developed by Dervan and coworkers. ${ }^{7}$ PIPs can sequence-specifically bind to the minor groove of double-stranded (ds) DNA based on the pairing rule that the antiparallel pair of pyrrole-imidazole can recognize a $\mathrm{C}$ $\mathrm{G}$ base pair, and pyrrole-pyrrole can recognize $\mathrm{A}-\mathrm{T}$ or $\mathrm{T}-\mathrm{A}$ base pairs. ${ }^{8}$ PIPs also have strong binding affinity toward dsDNA. For example, the DNA-binding domain of natural transcription factor Zif268 has a dissociation constant $\left(K_{D}\right)$ of around $3 \mathrm{nM}$; however, in many cases, eight-ring hairpin PIP has a $K_{D}$ of $<1 \mathrm{nM}$ toward its target site. ${ }^{7,9}$ Therefore, PIPs are programmable dsDNA- binding molecules with high affinity similar to that of natural transcription factors.

There are abundant G4-forming sequences present in native DNAs, but they are usually present as duplex DNAs except for telomeric DNA. It remains challenging to selectively induce an individual G4 formation in the context of stable dsDNA. Herein, we designed and synthesized head-to-head hairpin PIP dimers with different linker lengths and their target dsDNA in a model G4-forming sequence. We show that PIP dimers with longer linkers could induce the structural change from dsDNA to G4 DNA. PIP dimers have been reported in some studies. For example, head-to-head hairpin PIP dimers were found to function as a clamp of nucleosome structure by recognizing two binding sites in nucleosomal DNA that had been brought into close proximity when the structure was formed. ${ }^{10}$ In this report, we anticipated that PIP dimers would recognize two target sites flanking the ends of a G4-forming sequence and would thereby induce G4 formation from dsDNA through their strong binding affinity and sequence specificity.

The strategy underlying this research and the design of compounds are illustrated in Figures 1 and 2. First, we designed the monomer PIP structure (1) based on previous reports. ${ }^{10,11} \mathrm{We}$ then synthesized three kinds of PIP dimers with different linker lengths (Figures 1A and 2). We also designed their target dsDNA with a model G4-forming sequence and their binding sites, which flanked both ends (Figure 1B). This sequence is known to be able to form the parallel-type G4 structure. ${ }^{12}$ The distance between two binding sites is $>15$ base pairs $(>50 \AA)$ in the duplex form, and the width and height of the G4 structure are estimated to be $25 \AA$ and $10 \AA$, respectively. ${ }^{12}$ The linker lengths of PIP dimers 2, 3, and 4 are also estimated to be 24,11 , and $7.4 \AA$, respectively. Based on this information, we considered that these binding sites would be separated distantly when the DNA is a duplex and that a PIP dimer molecule would bind to either site. However, we also reasoned that when the DNA forms a G4 structure, these binding sites would be brought into close proximity, allowing one PIP dimer molecule to bind to both sites. In other words, we anticipated that the structural change from dsDNA to G4 DNA could be induced by one PIP dimer molecule recognizing both target sites.

To investigate whether PIP dimers can truly induce the G4 formation from dsDNA, we first performed an electrophoresis mobility shift assay (Figure 3). According to a previous report, the bands of G4 DNA and dsDNA should be distinguishable. ${ }^{13}$ In this assay, $\mathrm{KCl}$ was added to the DNA solution to stabilize the $\mathrm{G} 4$ 


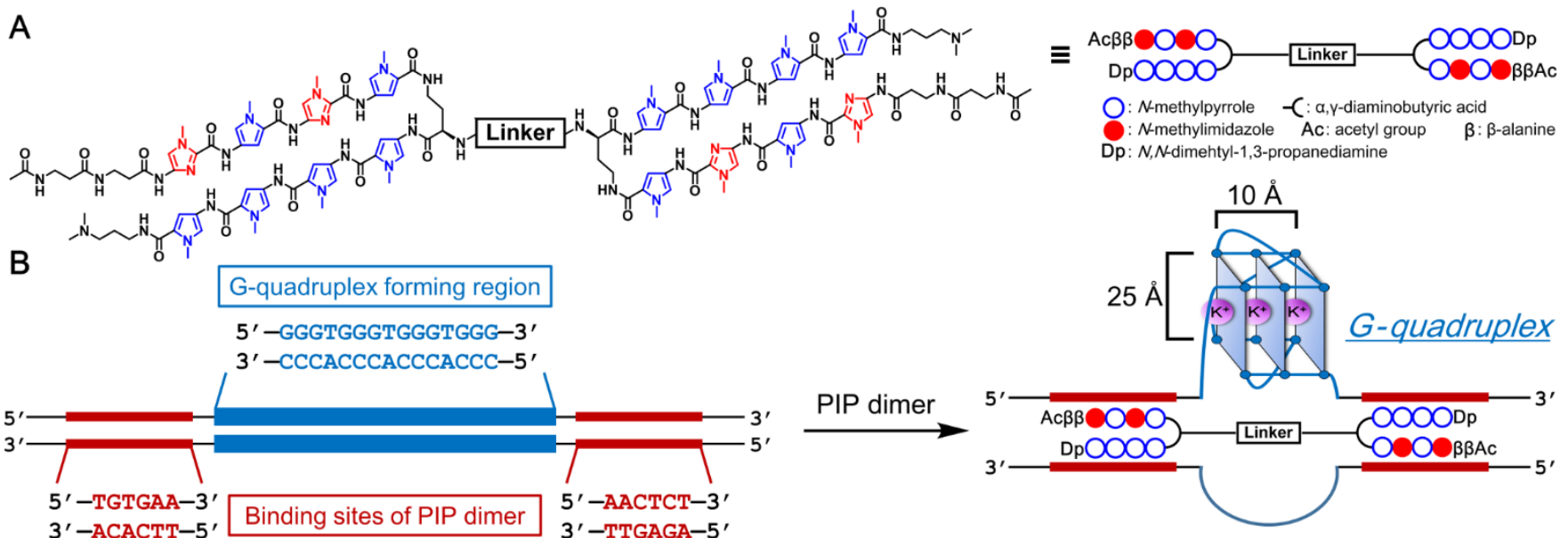

Figure 1. Schematic image of this research. We designed PIP dimers with different linker lengths (A) and their target dsDNA (B, left). We anticipated that the formation of the G4 structure from dsDNA would be induced by one PIP dimer molecule recognizing two binding sites flanking the G4-forming sequence (B).

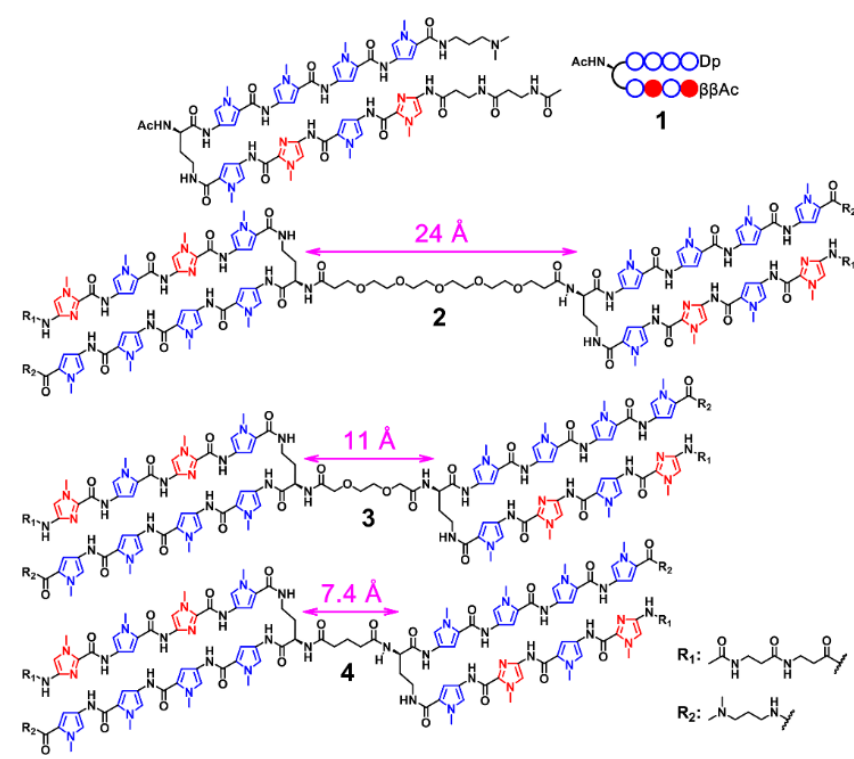

Figure 2. Chemical structures of the monomer PIP 1 and PIP dimers 2-4. The linker lengths of $\mathbf{2}, \mathbf{3}$, and $\mathbf{4}$ were estimated to be 24,11 , and $7.4 \AA$, respectively.

structure, and PEG 200 was also added to create molecular crowding conditions. ${ }^{13,14}$ After annealing of the G-rich strand and C-rich strand in the presence of $\mathrm{K}^{+}$and PEG 200, the DNA solution was incubated at $37{ }^{\circ} \mathrm{C}$ for $3 \mathrm{~h}$ with or without compounds $\mathbf{1 - 4}$, and each sample was resolved by native gel electrophoresis. As a positive control, DNA solution including a G-rich strand and poly-T strand (i.e., the complementary sequences of the G4-forming region were all replaced with $\mathrm{T}$ ) was used. The mobility indicated that a G4 structure was induced by PIP dimers with longer linkers 2 and 3, although the DNA totally formed a double-stranded structure in the absence of any compounds. The band induced by 2 was found to depend on $\mathrm{K}^{+}$and PEG, which suggests the formation of G4 (Figure S6). ${ }^{13,14}$

The intensity ratio of each band shown in Figure 3B was calculated using ImageJ software and the ratios are listed in Table $1 .^{15}$ As shown in this table and the gel images in Figure 3B, the G4 DNA ratio increased as the linker length became longer and the compound equivalents increased. This dependency on the linker length is consistent with our expectation (Figure 1B). That is, if the linker length were much shorter than the size of the G4 structure, one PIP dimer molecule would bind to either target site in the form of G4 DNA, which means that the PIP dimer would not have the driving force to induce $\mathrm{G} 4$ formation from dsDNA.

We also observed two slightly slower migrating bands than that of dsDNA, as indicated by blue arrows (in lanes $6-8,11-13$, and 14-16) and by the green arrow (faint in lane 15 and darker in lane 16). We considered that these bands were derived from one-PIPbinding dsDNA and two-PIPs-binding dsDNA, respectively, because the band of one-binding DNA became stronger as that of dsDNA got weaker, and similarly, the band of two-binding DNA became stronger as that of one-binding DNA became weaker. The reason why such bands were not distinguished with monomer PIP $\mathbf{1}$ may be that $\mathbf{1}$ has a smaller molecular weight than $\mathbf{2}-\mathbf{4}$ and its molecular size is also smaller than that of any of the dimers. As a result, it seems that the PIP dimers with longer linkers could induce $\mathrm{G} 4$ formation from dsDNA.

To confirm the G4 induction by PIP dimers, we next performed a transcription arrest assay (Figure 4). According to previous reports, transcription with T7 RNA polymerase is arrested by a G4 structure to produce a truncated RNA in addition to a full-length RNA. ${ }^{16,17}$ Therefore, we checked whether PIP dimers could cause a structural change from dsDNA to G4 DNA by detecting the production of truncated RNA. In this assay, we used the dsDNA with the same sequence as the dsDNA used in the band shift assay connected to the $\mathrm{T} 7$ promoter with a spacer sequence between them (Figure 4A). The truncated RNA at the T nearest to the G4forming sequence was $49 \mathrm{nt}$, and the full-length RNA was $81 \mathrm{nt}$. After annealing and incubation as used in the band shift assay, DNA solution was added to the transcription solution, and this was followed by the transcription reaction, template DNA digestion, denaturing of transcripts, and finally urea-denaturing gel electrophoresis. As in the band shift assay, the intensity ratio of each band was calculated using ImageJ software and the results are listed in Table $2 .^{15}$

As shown in Figure 4, an increase in the amount of truncated RNA was observed with $\mathbf{2}$, although a few truncated RNAs were produced in the samples without any compounds (lanes 2 and 10). It was found that there was little production of this RNA in the absence of $\mathrm{K}^{+}$or in the presence of $\mathrm{Li}^{+}$, which suggests that this RNA would be produced by transcription arrest at G4 (Figure S7). ${ }^{16}$ This result means that more G4 DNAs were present in the samples with 2 compared with those without any compounds, which is also consistent with the results of band shift assay. Above the band of the full-length RNA ( $81 \mathrm{nt}$ ), another slightly longer band of RNA was observed. As indicated in a previous report, this may be because T7 RNA polymerase can slip during transcription on the template DNA to produce RNAs 8-10 nt 


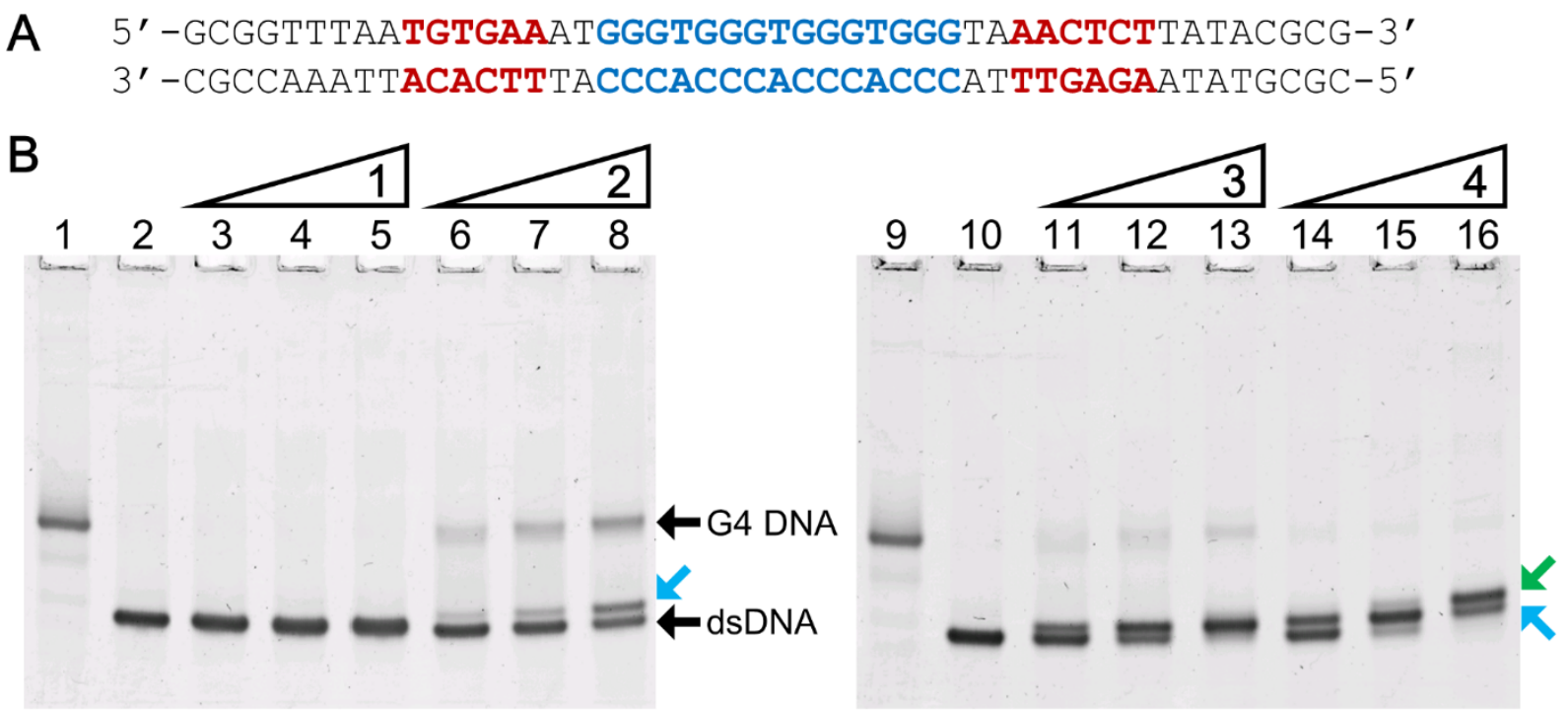

Figure 3. Electrophoresis mobility shift assay. (A) DNA sequences used in this assay. The blue regions are the G4-forming sequences, and the red regions are the binding sites of PIPs. For the positive control (lanes 1 and 9), the complementary sequences of the G4-forming region ( $3^{\prime}$-CCCACCCACCCACCC-5') were all replaced with T. (B) Results of native gel electrophoresis. G4 DNA formation was induced by PIP dimers and was dependent on the linker length and concentration of compounds. Lanes 1 and 9: positive control for G4 formation. Lanes 2 and 10: without any compounds. Lanes 3-5, 6-8, 11-13, and 14-16 relate to compounds 1, 2, 3, and 4 at $1.0,2.0$, and 5.0 eq, respectively.

Table 1. Band Intensity Ratios of G4 DNA, PIP-Binding dsDNA, and dsDNA in each Lane (\%) of Figure 3B.

\begin{tabular}{|c|c|c|c|c|c|c|c|c|c|c|c|c|}
\hline \multirow[b]{2}{*}{ Lane } & \multicolumn{3}{|c|}{ Monomer PIP 1} & \multicolumn{3}{|c|}{2 (Longer linker) } & \multicolumn{3}{|c|}{3 (Medium linker) } & \multicolumn{3}{|c|}{4 (Shorter linker) } \\
\hline & 3 & 4 & 5 & 6 & 7 & 8 & 11 & 12 & 13 & 14 & 15 & 16 \\
\hline G4 DNA & 0 & 0 & 0 & 19 & 25 & 31 & 10 & 11 & 11 & 1.8 & 1.7 & 2.1 \\
\hline $\begin{array}{l}\text { PIP-binding dsDNA } \\
\text { dsDNA }\end{array}$ & $100^{\mathrm{a}}$ & $100^{\mathrm{a}}$ & $100^{\mathrm{a}}$ & 12 & 16 & 30 & 33 & 53 & 89 & 47 & $\begin{array}{c}80(9.3)^{\mathrm{b}} \\
18\end{array}$ & $\begin{array}{c}98(59)^{\mathrm{b}} \\
0\end{array}$ \\
\hline
\end{tabular}

${ }^{a}$ The bands of dsDNA and PIP-binding dsDNA could not be distinguished because they had almost the same mobility.

${ }^{b}$ Values inside parentheses indicate the ratio of two-dimers-binding dsDNA (shown by the green arrow in Figure 3B).

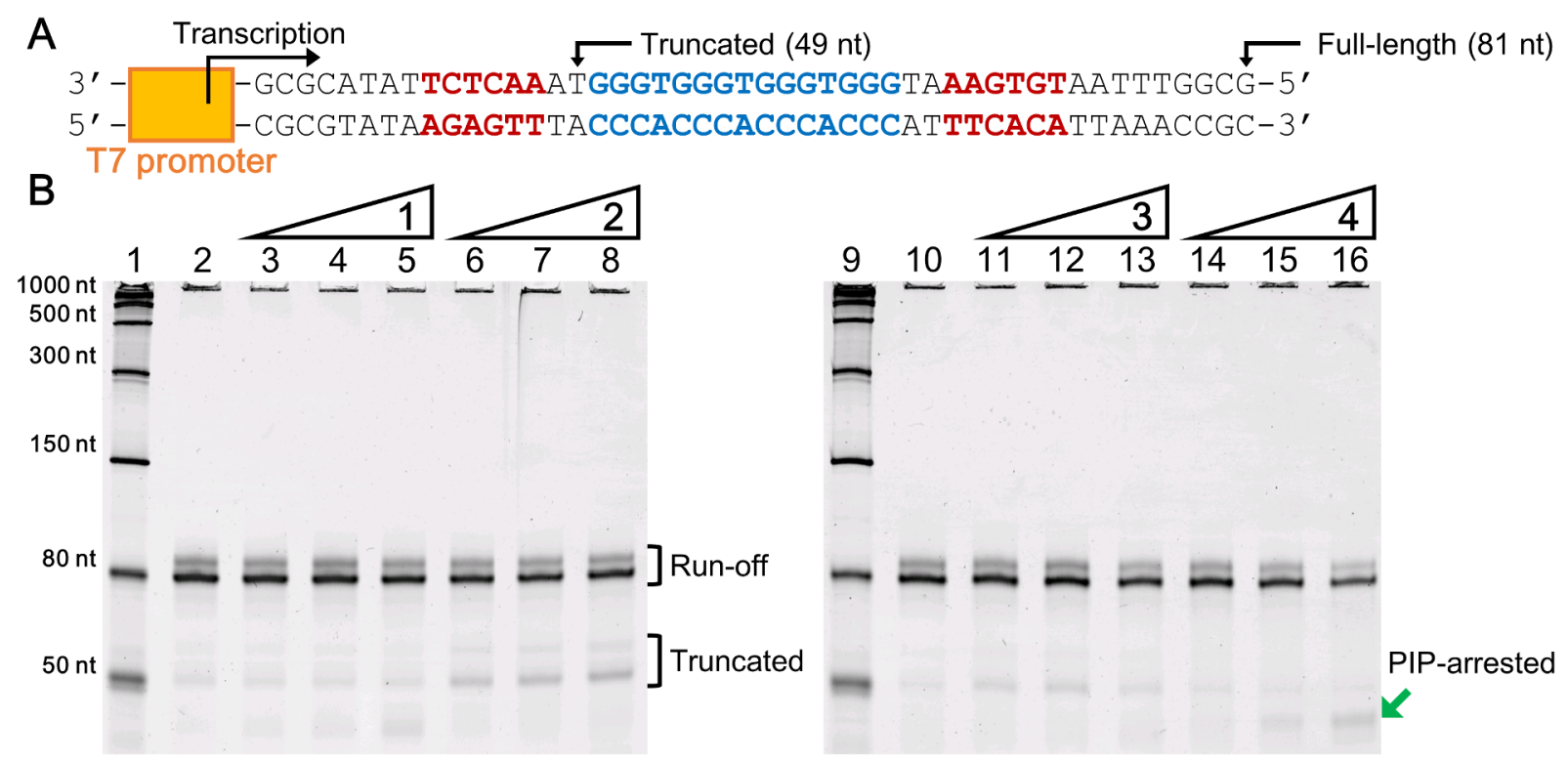

Figure 4. Transcription assay. (A) DNA sequences used in this assay. The T7 promoter was connected to the DNA used in the band shift assay with a spacer. (B) Results of denaturing gel electrophoresis of transcripts. Each transcript was identified based on its length predicted from the template DNA design (full-length: $81 \mathrm{nt}$, truncated: $49 \mathrm{nt}$ ). The ratio of truncated RNA was increased with 2 . Lanes 1 and 9: single-stranded RNA ladder. Lanes 2 and 10: without any compounds. Lanes 3-5, 6-8, 11-13, and 14-16 relate to compounds 1, 2, 3, and 4 at $1.0,2.0$, and 5.0 eq, respectively. 
Table 2. Band Intensity Ratios of Run-off Transcripts, Truncated Transcripts, and PIP-Arrested Transcripts in each Lane (\%) of Figure 4B.

\begin{tabular}{|c|c|c|c|c|c|c|c|c|c|c|c|c|c|c|}
\hline \multirow[b]{2}{*}{ Lane } & \multicolumn{2}{|c|}{ No PIPs } & \multicolumn{3}{|c|}{ Monomer PIP 1} & \multicolumn{3}{|c|}{2 (Longer linker) } & \multicolumn{3}{|c|}{3 (Medium linker) } & \multicolumn{3}{|c|}{4 (Shorter linker) } \\
\hline & 2 & 10 & 3 & 4 & 5 & 6 & 7 & 8 & 11 & 12 & 13 & 14 & 15 & 16 \\
\hline Run-off $^{\mathrm{a}}$ & 93 & 96 & 91 & 90 & 83 & 87 & 84 & 81 & 94 & 93 & 88 & 98 & 90 & 78 \\
\hline Truncated & 7.4 & 3.8 & 6.6 & 6.6 & 8.1 & 13 & 16 & 19 & 6.4 & 7.0 & 7.3 & 2.3 & 2.6 & 2.9 \\
\hline PIP-arrested & 0 & 0 & 2.7 & 3.6 & 8.5 & 0 & 0 & 0 & 0 & 0 & 4.9 & 0 & 7.6 & 20 \\
\hline
\end{tabular}

${ }^{a}$ This is the total ratio of full-length RNA and longer RNA produced by slippage of T7 RNA polymerase (observed above the full-length RNA band).

longer or shorter. ${ }^{16} \mathrm{We}$ also observed another band below that of the truncated RNA in lanes 5 and 16 (shown by the green arrow in Figure 4). Judging from its estimated length and the dependency on compound equivalents, this RNA may have been produced by transcription arrest by PIPs binding at their target sites. Although it was already confirmed that the transcription by RNA polymerase II was effectively arrested by PIP binding ${ }^{18}$, some studies reported that the transcription by T7 RNA polymerase was not arrested by noncovalent PIP binding. ${ }^{19,20}$ However, we think that this result is not contradictory to previous reports ${ }^{19,20}$ because the transcription condition in this assay was not same as in these reports; for example, we removed spermidine, which is a transcription activator, and reduced the amount of $\mathrm{Mg}^{2+}$, which is an essential factor for transcription, to show clearly the effects of PIPs on transcription. As a result, we could detect an increase in the amount of truncated RNA with PIP dimer 2, which indicates the induction of a G4 DNA by this compound.

In summary, we designed three kinds of head-to-head hairpin PIP dimers with different linker lengths, and their target dsDNA with a model G4-forming sequence between two target sites under the expectation that PIP dimers can induce G4 DNA formation from dsDNA because of their strong binding affinity and sequence specificity. An electrophoresis mobility shift assay showed that the induction of G4 formation was achieved with PIP dimers and that their induction abilities depended greatly on their linker length. G4 induction with PIP dimers was confirmed using a transcription arrest assay, which showed that the amount of truncated RNA produced by the G4 structure was increased by the PIP dimer with the longer linker. Combining the results of these two experimental approaches, we conclude that PIP dimers can induce the structural change from dsDNA to G4 DNA by recognizing two binding sites flanking the G4-forming sequence.

In this report, as a proof of concept, we designed DNA substrates with the model G4-forming sequence to simplify this research. G4-forming sequences in native genomic DNAs are generally more complicated. ${ }^{21}$ For example, in this research, the nucleotide-forming loop structure of the $\mathrm{G} 4$ comprised one $\mathrm{T}$ in each loop but has two or more nucleotides with a different composition in each loop in native sequences. Additionally, consecutive Gtracts involving $\mathrm{G} 4$ formation are not always four runs of three guanines, but could be four or more runs of two, three, or more guanines. However, for G4 induction using the approach described here, such complexity may not be important because the most important factors are the size of the G4 structure and the duplex sequences flanking both ends, and we could easily adjust the target sequences of PIPs based on the pairing rule. Consequently, it is possible that PIP dimers can be applied to the induction of the G4 structure in native sequences by editing the target sequences of PIPs to appropriate lengths. Moreover, it is also possible that the induction of other higher-order structures of DNA may be achieved using PIP dimers and the same strategy.

\section{ASSOCIATED CONTENT}

\section{Supporting Information}

The Supporting Information is available free of charge on the ACS Publications website at DOI: XXX

Experimental procedures, synthetic schemes, characterization data for 1-4 and their precursor PIP, further experiments of band shift assay and transcription assay, and DNA sequences lists for two assays including Figures S1-S7, Scheme S1 and Tables S1 and S2 (PDF)

\section{AUTHOR INFORMATION}

\section{Corresponding Authors}

*bando@kuchem.kyoto-u.ac.jp (T. Bando)

*hs@kuchem.kyoto-u.ac.jp (H. Sugiyama)

\section{ORCID}

Hiroshi Sugiyama: 0000-0001-8923-5946

\section{Notes}

The authors declare no competing financial interests.

\section{ACKNOWLEDGMENT}

We thank Dr. Chuanxin Guo for helping to make the figure for table of contents. This work was supported by JSPS KAKENHI to H. S. (16H06356), Basic Science and Platform Technology Program for Innovative Biological Medicine by Japan Agency for Medical Research and Development (AMED), and Platform Project for Supporting Drug Discovery and Life Science Research by AMED to H. S.

\section{REFERENCES}

(1) Jain, A.; Wang, G.; Vasquez, K. M. Biochimie 2008, 90, 1117.

(2) Brazda, V.; Laister, R. C.; Jagelska, E. B.; Arrowsmith, C. BMC Mol. Biol. 2011, 12, 33.

(3) Day, H. A.; Pavlou, P.; Waller, Z. A. E. Bioorg. Med. Chem. 2014, 22, 4407.

(4) Han, H; Hurley, L. H. Trends Pharmacol. Sci. 2000, 21, 136.

(5) Zahler, A. M.; Williamson, J. R.; Cech, T. R.; Prescott, D. M. Nature 1991, 350, 718 .

(6) Simonsson, T.; Pecinka, P.; Kubista, M. Nucleic Acids Res. 1998, 26, 1167.

(7) Trauger, J. W.; Baird, E. E.; Dervan, P. B. Nature 1996, 382, 559

(8) Blackledge, M. S.; Melander, C. Bioorg. Med. Chem. 2013, 21, 6101.

(9) Dervan, P. B.; Edelson, B. S. Curr. Opin. Struct. Biol. 2003, 13, 284.

(10) Edayathumangalam, R. S.; Weyermann, P.; Gottesfeld, J. M.; Dervan, P. B.; Luger, K. Proc. Natl. Acad. Sci. U.S.A. 2004, 101, 6864.

(11) Anandhakumar, C.; Li, Y.; Kizaki, S.; Pandian, G. N.; Hashiya, K.; Bando, T.; Sugiyama, H. ChemBioChem 2014, 15, 2647.

(12) Krauss, I. R.; Ramaswamy, S.; Neidle, S.; Haider, S.; Parkinson, G. N. J. Am. Chem. Soc. 2016, 138, 1226.

(13) Asamitsu, S.; Li, Y.; Bando, T.; Sugiyama, H. ChemBioChem 2016, $17,1317$.

(14) Zheng, K. W.; Chen, Z.; Hao, Y. H.; Tan, Z. Nucleic Acids Res. 2010, 38,327 .

(15) Schneider, C. A.; Rasband, W. S.; Eliceiri, K. W. Nat. Methods 2012, 9,671 .

(16) Tateishi-Karimata, H.; Isono, N.; Sugimoto, N. PLOS ONE 2014, 9, e90580. 
京都大学

A Self-archived copy in

KYOTO UNIVERSITY

Kyoto University Research Information Repository

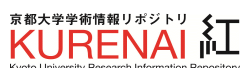

(17) Broxson, C.; Beckett, J.; Tornaletti, S. Biochemistry 2011, 50, 4162.

(18) Xu, L.; Wang, W.; Gotte, D.; Yang, F.; Hare, A. A.; Welch, T. R.;

Li, B. C.; Shin, J. H.; Chong, J.; Strathern, J. N.; Dervan, P. B.; Wang, D. Proc. Natl. Acad. Sci. U.S.A. 2016, 113, 12426.

(19) Asamitsu, S.; Kawamoto, Y.; Hashiya, F.; Hashiya, K.; Yamamoto, M.; Kizaki, S.; Bando, T.; Sugiyama, H. Bioorg. Med. Chem. 2014, 22, 4646 .
(20) Oyoshi, T.; Kawakami, W.; Narita, A.; Bando, T.; Sugiyama, H. J. Am. Chem. Soc. 2003, 125, 4752.

(21) Burge, S.; Parkinson, G. N.; Hazel. P.; Todd, A. K.; Neidle, S. Nucleic Acids Res. 2006, 34, 5402.

Table of Contents artwork

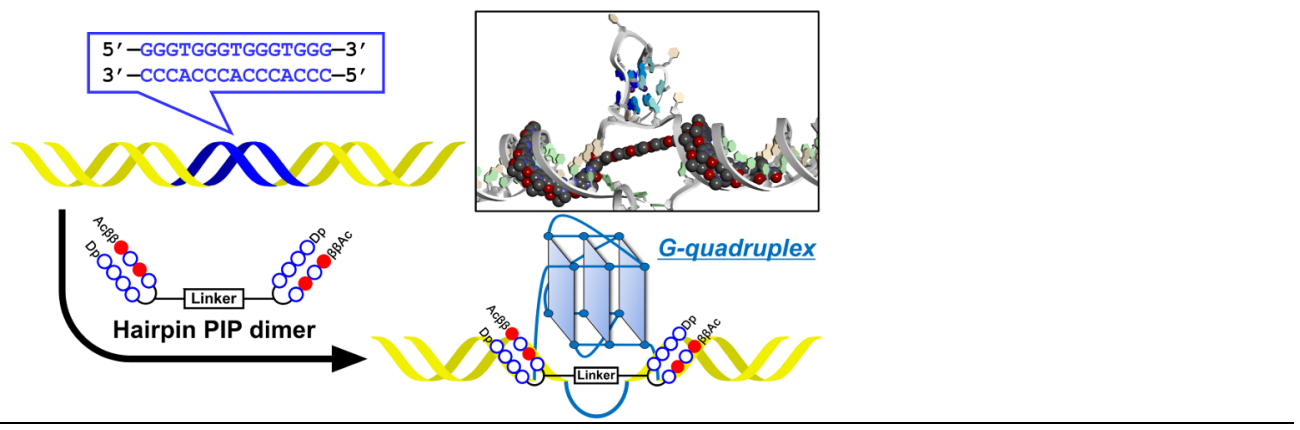




\section{Supporting Information}

\section{G-Quadruplex Induction by Hairpin Pyrrole-Imidazole Polyamide Dimer}

Shunsuke Obata ${ }^{\mathrm{a}}$, Sefan Asamitsu ${ }^{\mathrm{a}}$, Kaori Hashiya ${ }^{a}$, Toshikazu Bando,a , and Hiroshi Sugiyama*,a,b

${ }^{a}$ Department of Chemistry, Graduate School of Science, Kyoto University, Kitashirakawa-Oiwakecho, Sakyo-

ku, Kyoto 606-8502, Japan

'Institute for Integrated Cell-Material Sciences (WPI-iCeMS), Kyoto University, Yoshida-Ushinomiyacho, Sakyo-ku, Kyoto 606-8501, Japan

\section{S1. Experimental Section}

\section{$\underline{\text { General information of synthesis }}$}

The reagents and solvents were purchased from standard suppliers and used without further purification. Analytical reversed-phase high performance liquid chromatography (HPLC) was performed on a Jasco Engineering PU-2089 Plus pump and Jasco Engineering UV-2075 Plus detector $(254 \mathrm{~nm})$ using a Chemcobond 5-ODS-H reversed-phase column $(4.6 \times 150$ $\mathrm{mm}$, ChemcoPlus) heated to $40{ }^{\circ} \mathrm{C}$. As the eluent, acetonitrile (MeCN) and $0.1 \%$ trifluoroacetic acid (TFA) in water were used at a flow rate of $1.0 \mathrm{~mL} / \mathrm{min}$ in a linear gradient of $0-100 \% \mathrm{MeCN}$ for $40 \mathrm{~min}$. MALDI-TOF mass spectroscopy was carried out with the Microflex system (Bruker).

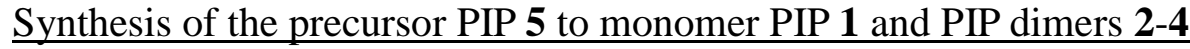

The synthesis of the basic structure of PIPs 1-5 was performed with Fmoc- $N$-methylpyrroleoxime resin $(82 \mathrm{mg}, 26.6 \mu \mathrm{mol} / 0.1 \mathrm{~g})$ by Fmoc solid phase synthesis on automated solid phase synthesizer PSSM-8 (Shimadzu), as described previously ${ }^{1,2}$. After the capping of N- 
terminal of the PIP with acetic anhydride, PIP was cleaved from resin with $N, N$-dimethyl1,3-propanediamine (Dp) by shaking at $45^{\circ} \mathrm{C}$ for $3 \mathrm{hrs}$. The reaction solution was dropped into diethyl ether, and the resulting powder was collected by centrifugation and dried in vacuo. The dried compound was dissolved into dichloromethane (DCM), and then TFA was added to the solution (DCM:TFA = 5:2) for the Boc-deprotection of the amine in the $\gamma$-turn. After the stirring at room temperature for $30 \mathrm{~min}$, DCM and TFA were evaporated. The residue was dissolved into DCM/MeOH mixed solvent (1:1) and then dropped into diethyl ether. After the centrifugation and drying, the collected crude sample was purified by reversedphase column chromatography using the CombiFlash Rf with 4.3 g C18 RediSep Rf reversed-phase flash column (Teledyne Isco, Inc). As the mobile phases, $\mathrm{MeCN}$ and $0.1 \%$ TFA in water were used. Finally, the precursor PIP 5 was obtained as off-white powder. HPLC and MALDI-TOF mass spectroscopy were carried out to identify the synthetic compound.

\section{Synthesis of monomer PIP 1}

The precursor PIP 5 was dissolved into DMF, and then the solution was dropped into $20 \%$ acetic anhydride in DMF and shaken at room temperature for $70 \mathrm{~min}$. The reaction solution was dropped into diethyl ether and the resulting powder was collected and dried in vacuo.

The crude sample was purified by reversed-phase HPLC on a Jasco Engineering PU-2080 Plus pump, Jasco Engineering UV-2075 Plus detector (254 nm), Jasco Engineering MX2080-32 mixer and Jasco Engineering DG-2080-54 degasser using a Chemcobond 5-ODS-H reversed-phase column $(4.6 \times 150 \mathrm{~mm})$ heated to $40{ }^{\circ} \mathrm{C}$. As the eluent, $\mathrm{MeCN}$ and $0.1 \% \mathrm{TFA}$ in water were used at a flow rate of $1.0 \mathrm{~mL} / \mathrm{min}$ in a linear gradient of $21-61 \% \mathrm{MeCN}$ for 30 min. As the result, monomer PIP 1 was obtained as off-white powder. HPLC and MALDITOF mass spectroscopy were performed to identify the synthetic compound. 
Synthesis of PIP dimer 2 with the longer linker.

The precursor PIP 5 was dissolved into DMF. After $N, N$-diisopropylethylamine (DIEA) was added, $N$-hydroxysuccinimide (NHS) ester of the longer linker (Bis-PEG5-NHS ester, Quanta BioDesign) in DMF was also added and shaken at room temperature for about $12 \mathrm{hrs.} \mathrm{After}$ that, the synthetic compound was recrystallized with diethyl ether and purified by reversedphase HPLC on a Jasco Engineering PU-2080 Plus pump, Jasco Engineering UV-2075 Plus detector (254 nm), Jasco Engineering MX-2080-32 mixer and Jasco Engineering DG-208054 degasser using a Chemcobond 5-ODS-H reversed-phase column $(4.6 \times 150 \mathrm{~mm})$ heated to $40{ }^{\circ} \mathrm{C}$. As the eluent, $\mathrm{MeCN}$ and $0.1 \%$ TFA in water were used at a flow rate of $1.0 \mathrm{~mL} / \mathrm{min}$ in a linear gradient of $23-63 \% \mathrm{MeCN}$ for $30 \mathrm{~min}$. Finally, PIP dimer 2 was obtained as offwhite powder. HPLC and MALSI-TOF mass spectroscopy were performed.

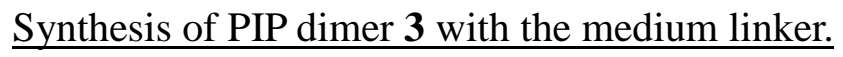

The condensing agent (HCTU, Peptide) and the medium linker $\left(\mathrm{PEG}_{2}-\left(\mathrm{CH}_{2} \mathrm{CO}_{2} \mathrm{H}\right)_{2}\right.$, BroadPharm) were dissolved into DMF and DIEA was also added. After the activation of carboxylic acid, the precursor PIP 5 in DMF was added and shaken at room temperature over $12 \mathrm{hrs}$. After that, the synthetic compound was recrystallized with diethyl ether and purified by reversed-phase HPLC on a Jasco Engineering PU-2080 Plus pump, Jasco Engineering UV-2075 Plus detector (254 nm), Jasco Engineering MX-2080-32 mixer and Jasco Engineering DG-2080-54 degasser using a Chemcobond 5-ODS-H reversed-phase column $(4.6 \times 150 \mathrm{~mm})$ heated to $40^{\circ} \mathrm{C}$. As the eluent, $\mathrm{MeCN}$ and $0.1 \%$ TFA in water were used at a flow rate of $1.0 \mathrm{~mL} / \mathrm{min}$ in a linear gradient of $23-63 \% \mathrm{MeCN}$ for $30 \mathrm{~min}$. Finally, PIP dimer $\mathbf{3}$ was obtained as off-white powder. HPLC and MALSI-TOF mass spectroscopy were performed. 


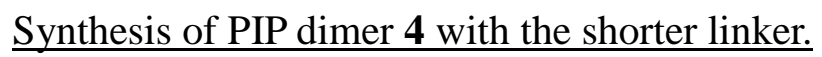

The precursor PIP 5 was dissolved into DMF. After DIEA was added, NHS ester of the shorter linker ( $N, N^{\prime}$-disuccinimidyl glutarate, Wako) in DMF was also added and shaken at room temperature for over $24 \mathrm{hrs}$. After that, the synthetic compound was recrystallized with diethyl ether and purified by reversed-phase HPLC on a Jasco Engineering PU-2089 Plus pump and Jasco Engineering UV-2075 Plus detector (254 nm) using a COSMOSIL 5C $18^{-}$ MS-II reversed-phase column (4.6 ID × $150 \mathrm{~mm}$, nacalai tesque). As the eluent, $\mathrm{MeCN}$ and $0.1 \%$ TFA in water were used at a flow rate of $1.0 \mathrm{~mL} / \mathrm{min}$ in a linear gradient of $23-63 \%$ $\mathrm{MeCN}$ for $30 \mathrm{~min}$. Finally, PIP dimer 4 was obtained as off-white powder. HPLC and MALSI-TOF mass spectroscopy were performed.

\section{Electrophoresis mobility shift assay}

The DNAs used in this assay (G-rich strand, C-rich strand and poly-T strand) were purchased from Sigma-Aldrich. 2 DNA strands (G-rich one and C-rich one) were annealed in $10 \mu \mathrm{L}$ buffer containing $10 \mathrm{mM}$ Tris $\cdot \mathrm{HCl}(\mathrm{pH} 8.0), 30 \mathrm{mM} \mathrm{KCl}, 50 \mathrm{mM} \mathrm{NaCl}$ and $20 \mathrm{w} / \mathrm{v} \%$ PEG 200 by $95{ }^{\circ} \mathrm{C}$ heating for $5 \mathrm{~min}$ and following gradual cooling to $35^{\circ} \mathrm{C}$ for $60 \mathrm{~min}\left(-1{ }^{\circ} \mathrm{C}\right.$ /min) with Thermal Cycler. For the positive control, G-rich one and poly-T one were used with the buffer containing $10 \mathrm{mM}$ Tris $\cdot \mathrm{HCl}$ (pH 8.0), $100 \mathrm{mM} \mathrm{KCl}$ and $40 \mathrm{w} / \mathrm{v} \%$ PEG 200. The concentration of each DNA strand was $200 \mathrm{nM}$. After the annealing, $1 \mu \mathrm{L} 10 \%$ DMSO in water with or without compounds 1-4 was added and then incubated at $37{ }^{\circ} \mathrm{C}$ for $3 \mathrm{hrs}$ (compounds: 1.0, 2.0 or 5.0 eq). Each sample was mixed with $6 \times$ Blue/Orange Loading Dye (Wako) and resolved by native polyacrylamide gel electrophoresis with $12 \%$ gel containing $1 \times \mathrm{TBE}$ and $50 \mathrm{mM} \mathrm{KCl}$, and running buffer containing $1 \times \mathrm{TBE}$ and $50 \mathrm{mM} \mathrm{KCl}$. Loaded amount was $3.0 \mu \mathrm{L}$ and electrophoresis was performed by $100 \mathrm{~V}$ for $80 \mathrm{~min}$ at $4{ }^{\circ} \mathrm{C}$. After the electrophoresis, gels were stained with SYBR Gold (Invitrogen) for 20 min and then 
imaged on an FLA-3000 Fluorescent Image Analyzer (Fujifilm).

\section{$\underline{\text { Transcription arrest assay }}$}

2 DNA strands used in this assay were purchased from Sigma-Aldrich. They were annealed in $5 \mu \mathrm{L}$ buffer containing $10 \mathrm{mM}$ Tris $\cdot \mathrm{HCl}(\mathrm{pH} 8.0), 40 \mathrm{mM} \mathrm{KCl}, 10 \mathrm{mM} \mathrm{NaCl}$ and 10 w/v\% PEG 200 by $95^{\circ} \mathrm{C}$ heating for 5 min and following gradual cooling to $35^{\circ} \mathrm{C}$ for 60 $\min \left(-1^{\circ} \mathrm{C} / \mathrm{min}\right)$ with Thermal Cycler. After the annealing, $1 \mu \mathrm{L} 10 \%$ DMSO in water with or without compounds 1-4 was added and then incubated at $37^{\circ} \mathrm{C}$ for 3 hrs (compounds: 1.0, 2.0 or $5.0 \mathrm{eq}$ ). After that, $2.5 \mu \mathrm{L}$ of this DNA solution and $7.5 \mu \mathrm{L}$ transcription solution were mixed and transcription reaction was performed for $60 \mathrm{~min}$ at $37^{\circ} \mathrm{C}$. The final reaction buffer contained $10 \mathrm{mM}$ Tris $\cdot \mathrm{HCl}(\mathrm{pH} 8.0), 40 \mathrm{mM} \mathrm{KCl}, 10 \mathrm{mM} \mathrm{NaCl}, 10 \mathrm{w} / \mathrm{v} \%$ PEG 200, $5 \mathrm{mM}$ $\mathrm{MgCl}_{2}, 5 \mathrm{mM}$ DTT, $2.5 \mathrm{mM}$ NTPs (Takara Bio Inc.), $50 \mathrm{nM}$ dsDNA, 25 U T7 RNA polymerase (Takara Bio Inc.) and $10 \mathrm{U}$ RNase inhibitor (Takara Bio Inc.). After the transcription, $10 \mathrm{U}$ DNase I (Takara Bio Inc.) and $65 \mathrm{mM} \mathrm{CaCl}_{2}$ solution (for the activation of DNase I) were added. Final concentration of $\mathrm{CaCl}_{2}$ was $5 \mathrm{mM}$, and DNA strands were digested at $37{ }^{\circ} \mathrm{C}$ for 60 min. Each sample was mixed with $2 \times$ RNA Loading Dye (New England Biolabs). As the ladder sample, $0.5 \mu \mathrm{L}$ of Low Range ssRNA Ladder (New England Biolabs) was mixed with $4.0 \mu \mathrm{L}$ of the loading dye. After the denaturalization of samples and the ladder sample by $95^{\circ} \mathrm{C}$ heating for $5 \mathrm{~min}$ and following immediate cooling with ice water for $5 \mathrm{~min}$, each sample was resolved by urea-denaturing polyacrylamide gel electrophoresis with $10 \%$ gels containing $1 \times \mathrm{TBE}$ and $7 \mathrm{M}$ urea, and running buffer containing $1 \times \mathrm{TBE}$. Loaded amount was $4.0 \mu \mathrm{L}$ and electrophoresis was performed by $180 \mathrm{~V}$ for $60 \mathrm{~min}$ at room temperature. After the electrophoresis, gels were stained with SYBR Gold (Invitrogen) for 20 min and then imaged on an FLA-3000 Fluorescent Image Analyzer (Fujifilm). 


\section{S2. Supporting Scheme, Figures and Tables}

Scheme S1. Synthetic scheme of PIP 1-5.

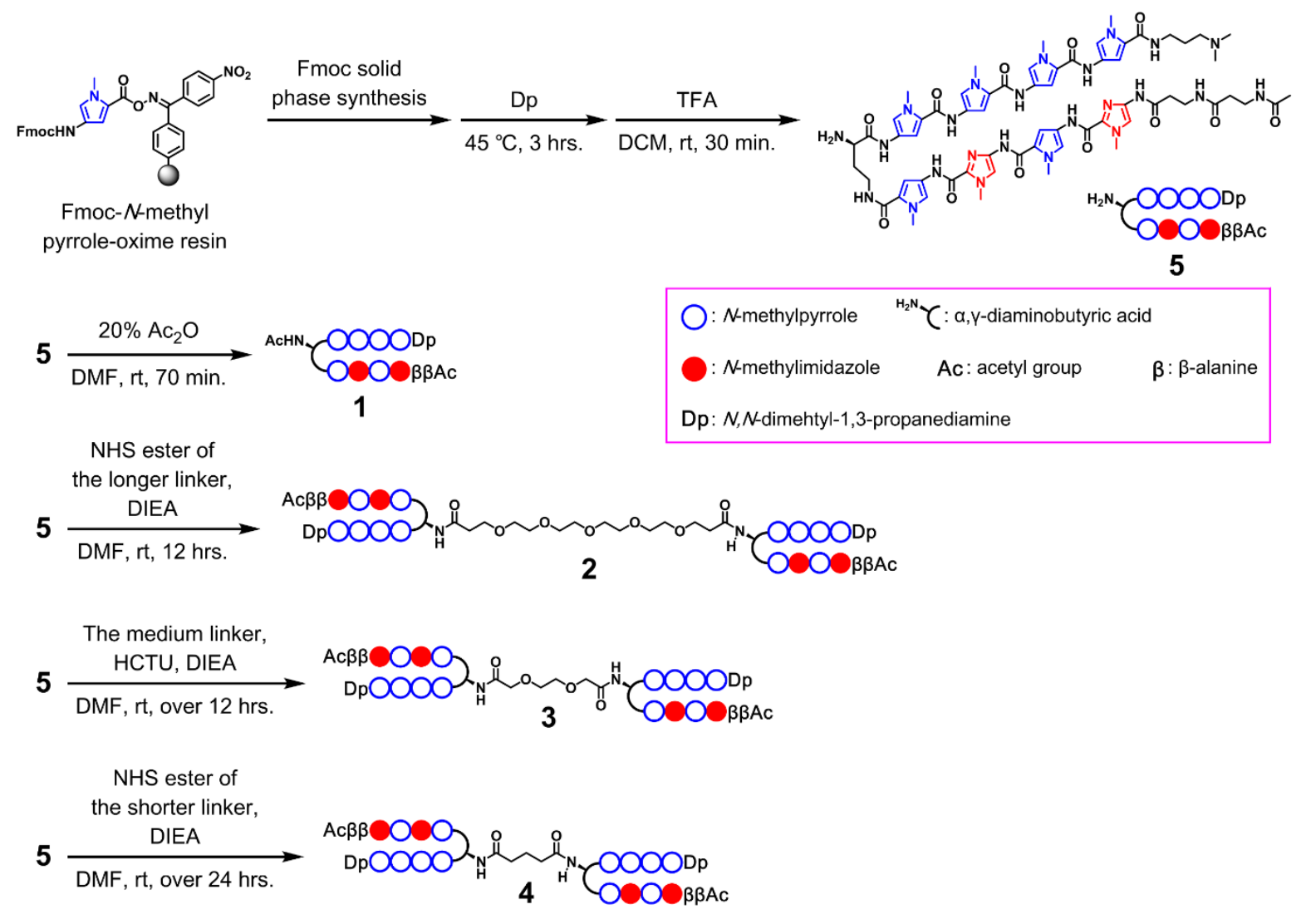



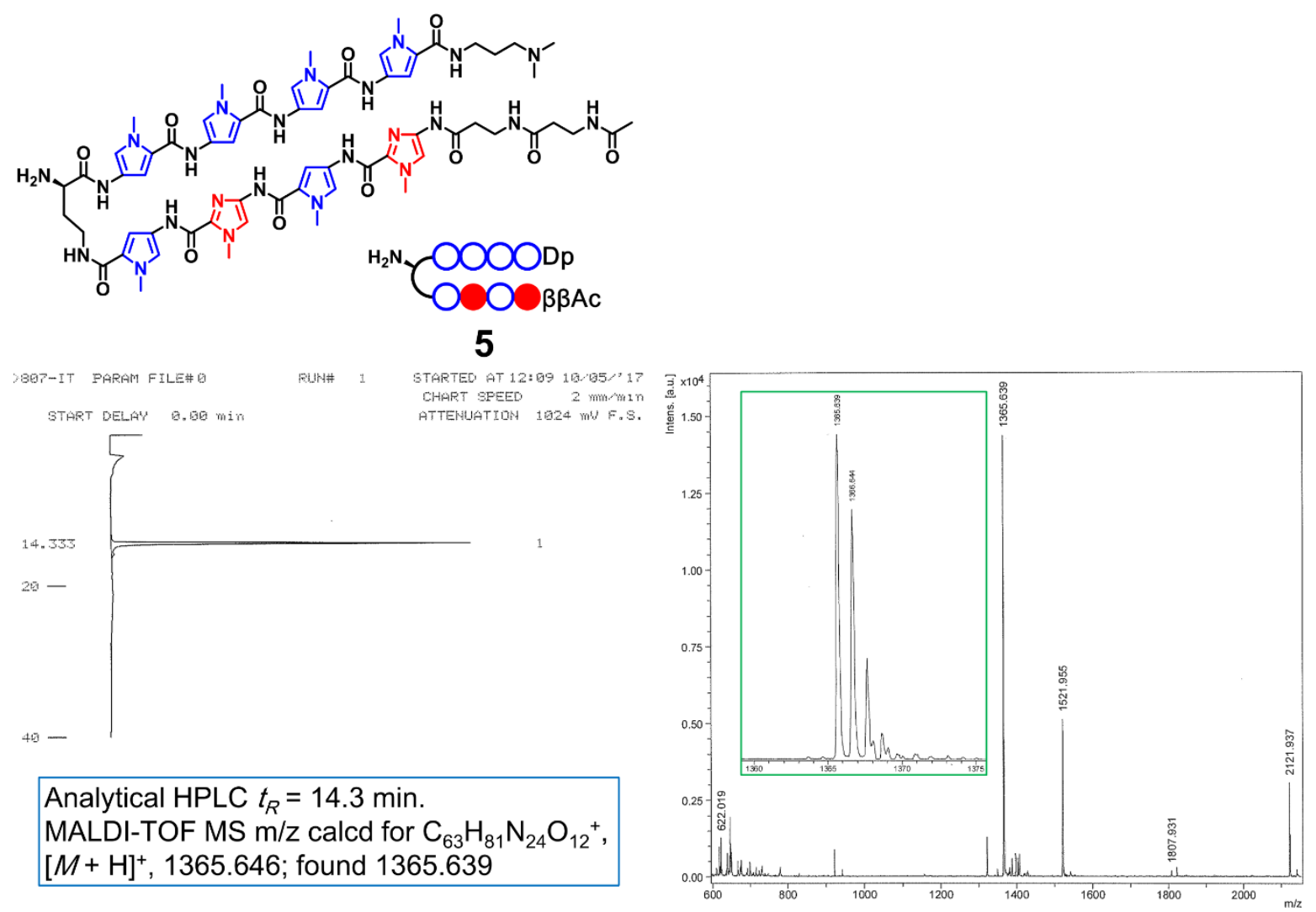

Figure S1. Chemical structure, HPLC chart and mass spectrum (inset; magnified figure of the target peak) of the precursor PIP 5. 

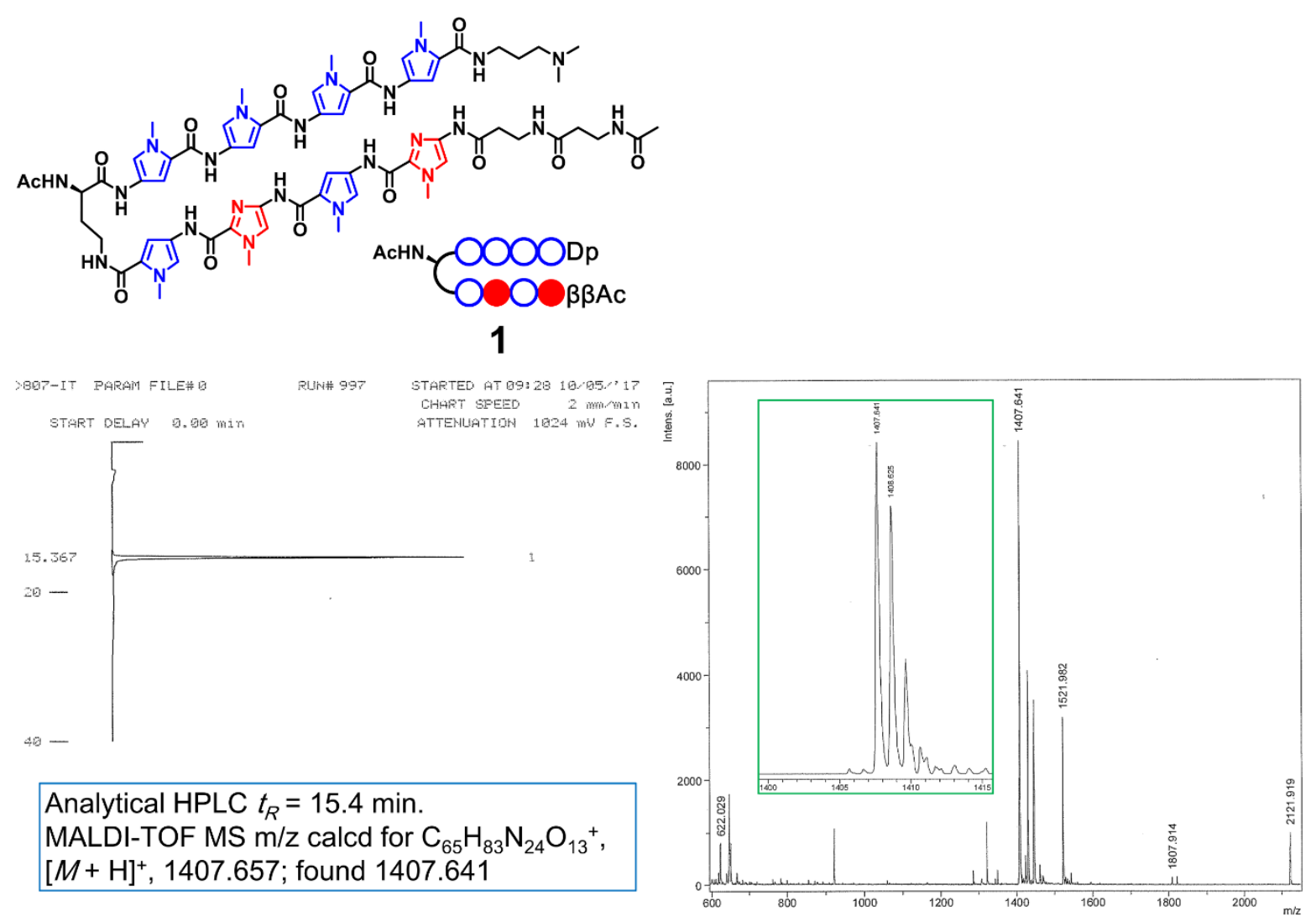

Figure S2. Chemical structure, HPLC chart and mass spectrum (inset; magnified figure of the target peak) of monomer PIP 1. 

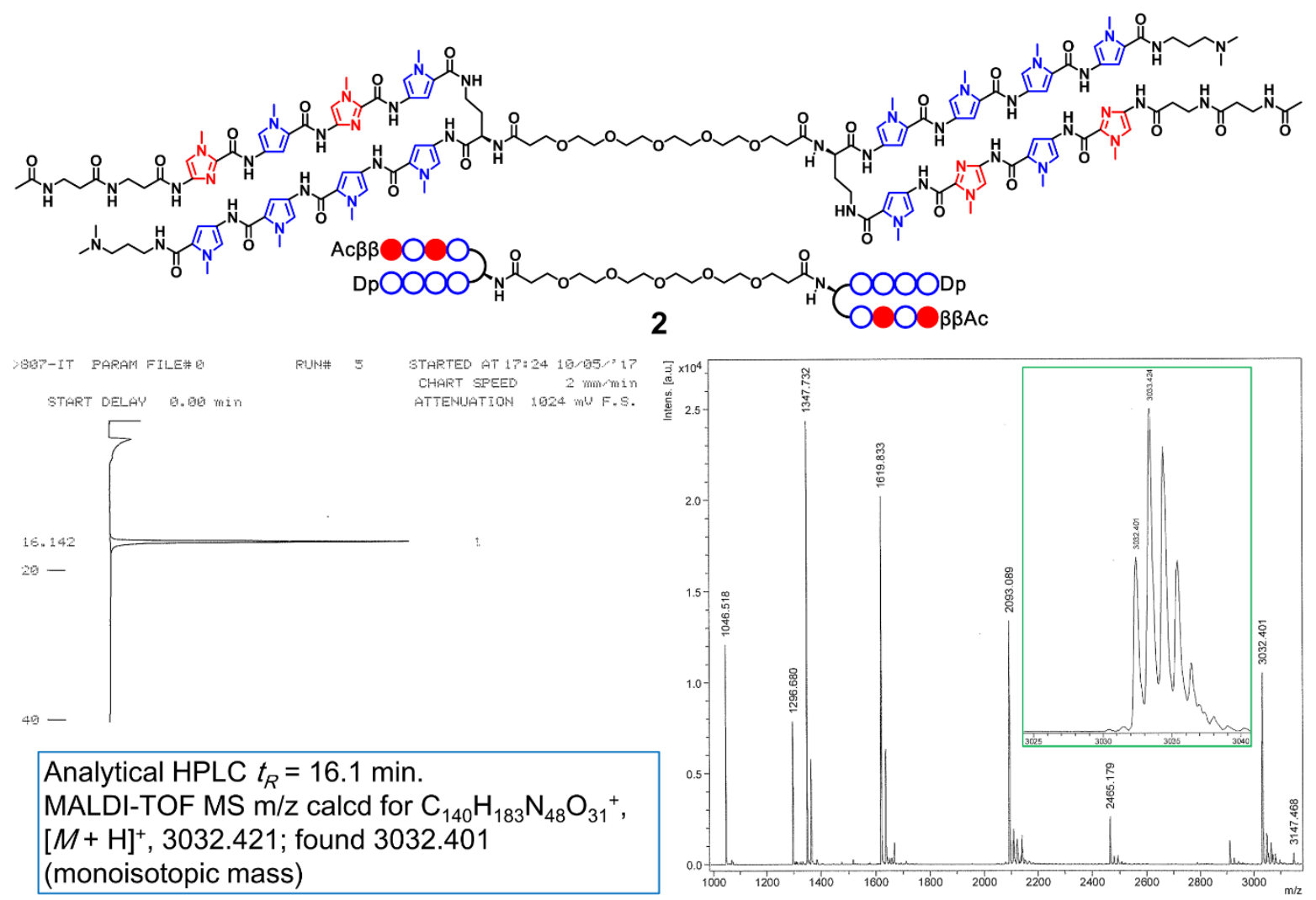

Figure S3. Chemical structure, HPLC chart and mass spectrum (inset; magnified figure of the target peak) of PIP dimer with the longer linker 2. 

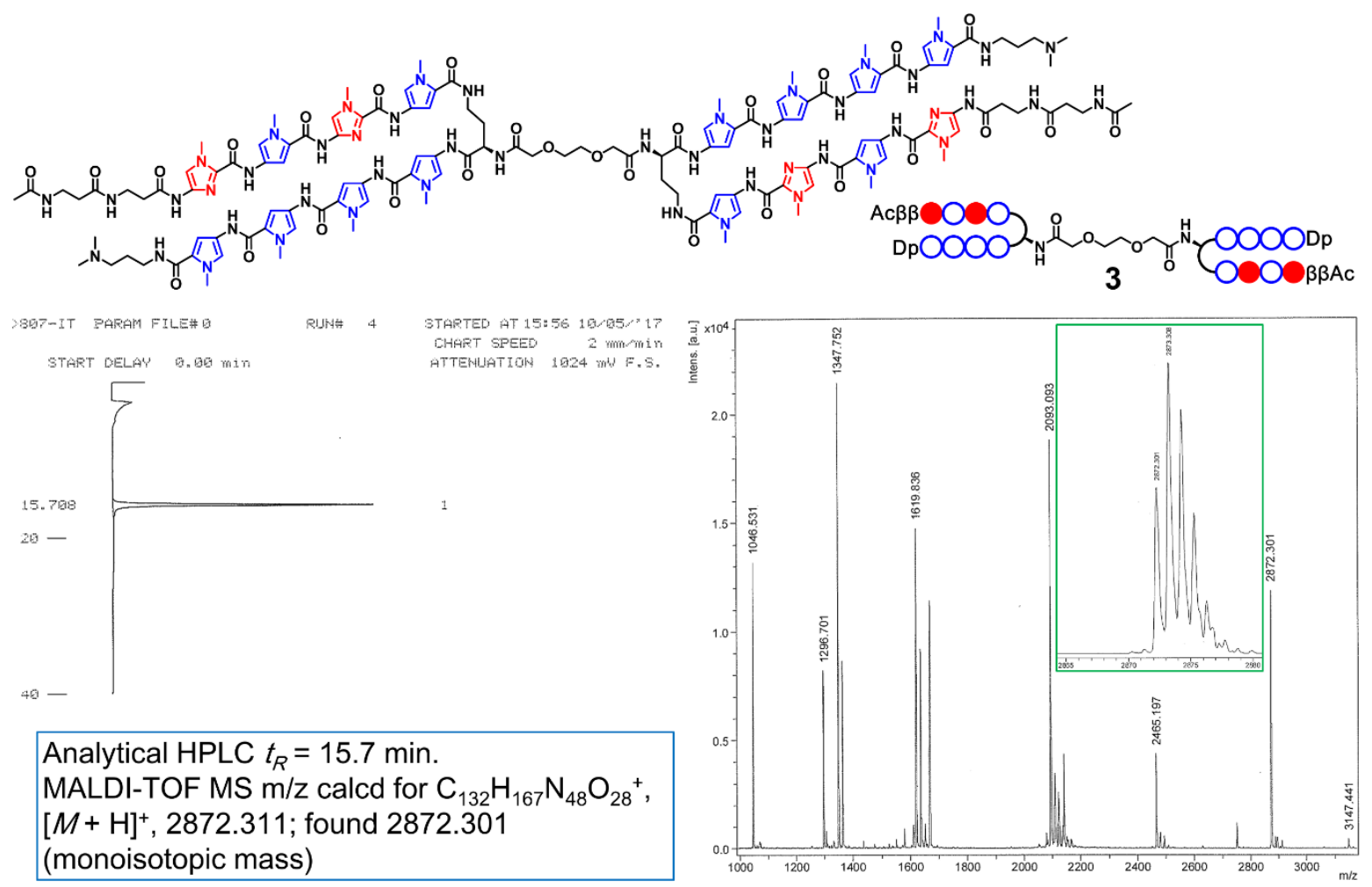

Figure S4. Chemical structure, HPLC chart and mass spectrum (inset; magnified figure of the target peak) of PIP dimer with the medium linker 3. 

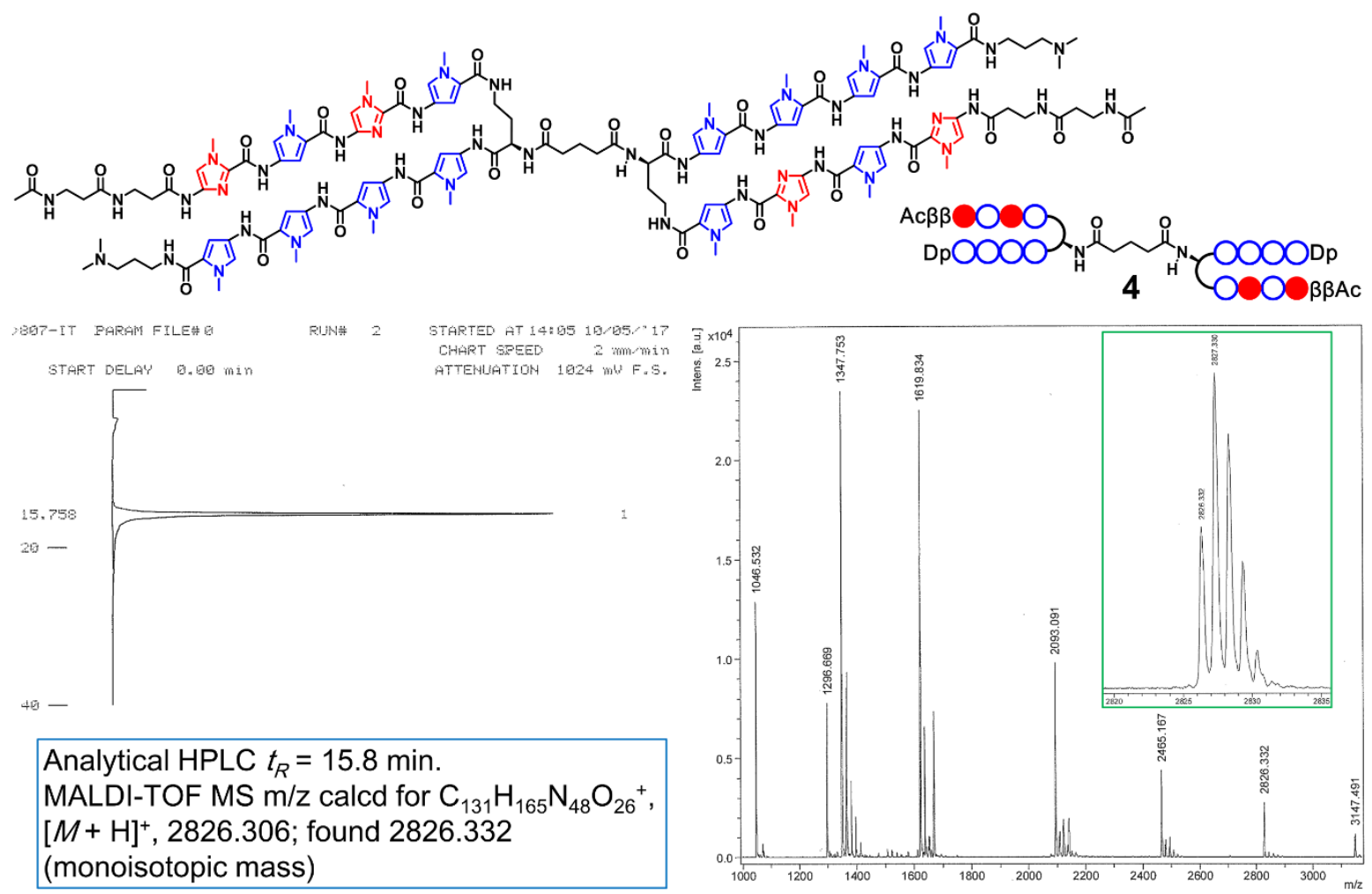

Figure S5. Chemical structure, HPLC chart and mass spectrum (inset; magnified figure of the target peak) of PIP dimer with the shorter linker 4. 


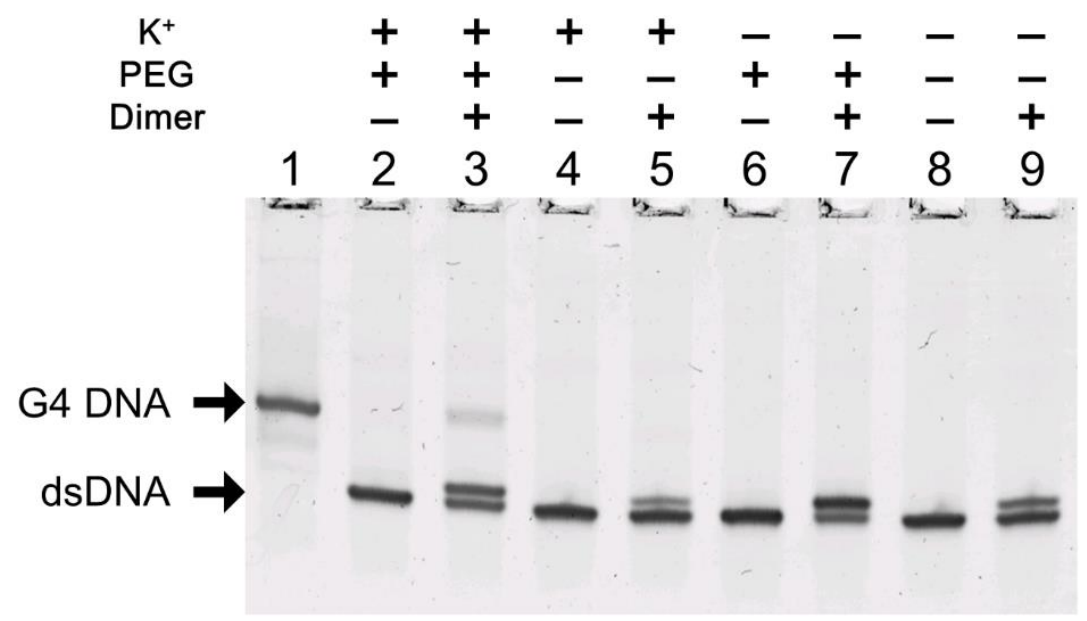

Figure S6. Dependency of the band induced by PIP dimer 2 on $\mathrm{K}^{+}$and PEG, confirmed by electrophoresis mobility shift assay. This result suggests that the band should be G4 DNA. Sample preparation was conducted as described above, but slightly modified. Lane 1: positive control for G4 formation. Lane 2-9: samples with (+) or without (-) $30 \mathrm{mM} \mathrm{KCl,}$ with (+) or without (-) 20 w/v\% PEG 200, and with (+) or without (-) 5.0 eq of PIP dimer 2. 


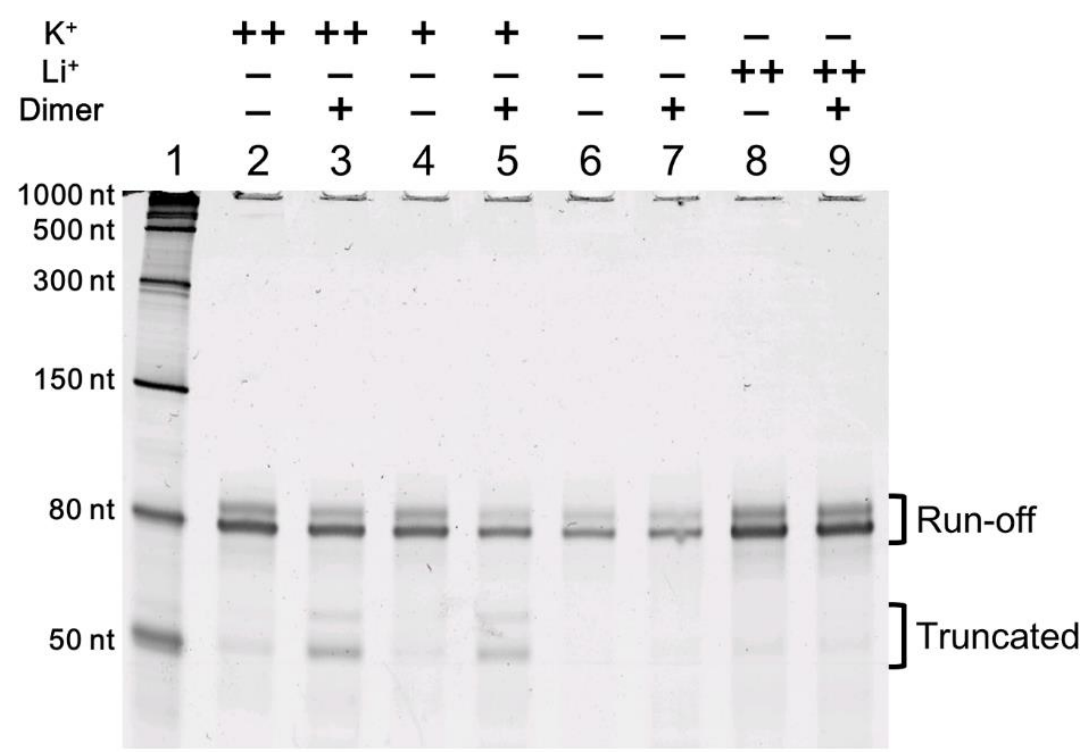

Figure S7. Dependency of the truncated RNA induced by PIP dimer 2 on $\mathrm{K}^{+}$, confirmed by transcription arrest assay. This result suggests that the RNA should be produced by the transcription arrest at G4 structure. Sample preparation was conducted as described above, but slightly modified. Lane 1: single-stranded RNA ladder. Lane 2-9: samples with (++, 40 $\mathrm{mM} ;+, 20 \mathrm{mM}$ ) or without (-) $\mathrm{KCl}$, with (++) or without (-) $40 \mathrm{mM} \mathrm{LiCl}$, and with (+) or without (-) 5.0 eq of PIP dimer 2. 
Table S1. DNA sequences used in band shift assay.

\begin{tabular}{|c|c|}
\hline Strand & Sequence \\
\hline G-rich & 5'-GCGGTTTAATGTGAAATGGGTGGGTGGGTGGGTAAACTCTTATACGCG-3' \\
\hline C-rich & 5'-CGCGTATAAGAGTTTACCCACCCACCCACCCATTTCACATTAAACCGC-3' \\
\hline Poly-T & 5'-CGCGTATAAGAGTTTATTTTTTTTTTTTTTTATTTCACATTAAACCGC-3' \\
\hline
\end{tabular}

Table S2. DNA sequences used in transcription assay.

\begin{tabular}{|c|c|}
\hline Strand & \\
\hline \multirow{2}{*}{ Template } & Sequence \\
\hline 'T'-GCGGTTTAATGTGAAATGGGTGGGTGGGTGGGTAAACTCTTATACGCG- & -TTCGTCGTTAGTCGGTACTTCATCCCTATAGTGAGTCGTATTAGGTATC-3' \\
\hline Complementary & 5'-GATACCTAATACGACTCACTATAGGGATGAAGTACCGACTAACGACGATGTTACAA- \\
& -CGCGTATAAGAGTTTACCCACCCACCCACCCATTTCACATTAAACCGC-3' \\
\hline
\end{tabular}

\section{S3. References}

(1) Sawatani, Y.; Kashiwazaki, G.; Chandran, A.; Asamitsu, S.; Guo, C.; Sato, S.; Hashiya, K.; Bando, T.; Sugiyama, H. Bioorg. Med. Chem. 2016, 24, 3603.

(2) Syed, J.; Pandian, G. N.; Sato, S.; Taniguchi, J.; Chandran, A.; Hashiya, K.; Bando, T.; Sugiyama, H. Chem. Biol. 2014, 21, 1370. 